\title{
Performance and Exhaust Emissions Using Blends on VCR Diesel Engine with Varying Compression Ratio of Hibiscus Oil
}

\author{
G.Pavan ${ }^{1}$, M.Rajesh ${ }^{2}$, K.Srinivas ${ }^{3}$ \\ ${ }^{1}$ M.Tech Student, Thermal engineering, V.R Siddhartha Engineering College, JNTU \\ ${ }^{2}$ Assistant Professor, Mechanical Engineering, V.R Siddhartha Engineering College, JNTU \\ ${ }^{3}$ Assistant Professor, Mechanical Engineering, V.R Siddhartha Engineering College, JNTU \\ Vijayawada, Andhra Pradesh, India
}

\begin{abstract}
Increasing the consumption of fuel in power and automobile sector, increase the pollution of the environment. Smoke and $\mathrm{NO}_{\mathrm{x}}$ are main pollutants of emission from diesel engine and it is very difficult to control them simultaneously Petroleum based fuels is a finite resource that is rapidly depleting. Consequently, petroleum reserves are not sufficient enough to last many years. Biodiesel is one of the alternative fuel made from vegetable oil, friendly for environment and has no effect on health and can reduce the emission compared with diesel fuel. In this paper will be examined the use of dieselhibiscus oil mixtures on (a single cylinder, direct ignition, four stroke, vertical, water cooled, naturally aspirated, variable compression ratio diesel engine). For those mixtures at B15 and B25 at compression ratios 13.5:1, 16.5:1 and 18:1 the brake thermal efficiency, mechanical efficiency and exhaust gas temperature. The gas emissions of carbon monoxide (CO), carbon dioxide $\left(\mathrm{CO}_{2}\right)$ and nitrogen oxide $\left(\mathrm{NO}_{\mathrm{x}}\right)$, are being measured.
\end{abstract}

Keywords - Bio fuels, hibiscus oil, engine performance and emissions.

\section{INTRODUCTION}

The objective of this dissertation is to investigate the performance and emission characteristic of a VCR diesel engine fuelled with Hibiscus-Diesel blend. Worldwide increase of demand for diesel fuel and environmental emission control has led to considerable research for better fuel formulations and thus reduction in smoke and particle levels. However, it is difficult to achieve the required emission standards with engine improvements alone. Blending the diesel with different vegetable oils has proven to be an alternative method to achieve the low emission and better performance diesel combustion. This has been the focal point of most researches in this field with in last two decades.

India's environment is constantly under the increasing pressure imposed by the rapid urbanization coupled with the rapid growth in the population. Increasing population, leading to an increase in number of vehicles and growth in the industrial and power sectors are exerting tremendous pressure on the atmosphere.

Major polluting industries and automobiles emit tones of pollutants every day, thereby leading to the deterioration in air quality and exposing citizens to greater health risks.

\section{Health Effects of Diesel Engine Emission}

Diesel emission has the potential to cause adverse health effects. These effects include cancer and other pulmonary and cardiovascular diseases. Diesel exhaust, in addition to generating other pollutants, is a major contributor to particulate matter pollution in most places in the world. More recently the possible effects of fine particles below $10 \mu \mathrm{m}$ on respiratory morbidity and mortality, especially in subjects with established chest disease, have been broached. There is also some evidence that the chronic inhalation of diesel fumes leads to the development of cough and sputum. Higher exposures may lead to acute symptoms, primarily affecting the conjunctivae and upper respiratory tract that is nearly always reversible within a few days. The human health effects of poor air quality are far reaching, but principally affect the body's respiratory system and the cardiovascular system.

\section{Alternative fuels}

So many vegetable oils are readily available to prepare blends with diesel and used in CI Engines. Among the various fuels, oxygen enriched oils are the most widely used. This is due to the participation of their oxygen in reactions and leading to a better combustion thus lowering the emissions. The presence of in such a high quantity will alter the physical and chemical properties such as: viscosity, density, volatility, and the cetane index, significantly.

In this paper, to study the performance and emission characteristics, the experimental setup consists of a variable compression ratio four stroke diesel engine, coupled with a computer. The mixtures used are the following: diesel-15\% hibiscus oil, diesel-25\% hibiscus oil at varying compression ratios of $13.5,16.5$ and 18 .

\section{LITERATURE SURVEY}

- Zlatica (2008) studied about the characteristics of biodiesel produced by two step alkali transesterification of waste sunflower oil using 
methanol and $\mathrm{KOH}$ as catalyst and at the same time investigated at influence of different purification methods on the properties and yields of the obtained products.

- Murugesan(2009) reviewed biodiesel production, methods of analysing, biodiesel standard, resources available, process developed, performance in internal combustion engines, teardown analysis of biodiesel, B20 operated vehicle, recommendation for development of bio fuels, environmental considerations, economic aspects and advantages.

- Tan et al (2010) utilized waste palm cooking oil instead of refined vegetable oils as the source of triglycerides for biodiesel production. Waste palm cooking oil contains several impurities, such as water and free fatty acids, which limit its application in catalytic transesterification process. Consequently, a catalyst free process using supercritical methanol was employed to investigate the potential of waste palm cooking oil as an economical feedstock for biodiesel production.

- PremAnand (2010) evaluated the combustion performance and exhaust emission characteristics of turpentine oil fuel blended with conventional diesel fuel in a diesel engine. The result showed that the addition of $30 \%$ turpentine oil with diesel produced higher brake power and net release rate with a net reduction in exhaust emissions such as $\mathrm{CO}, \mathrm{HC}, \mathrm{NO}_{\mathrm{X}}$ smoke and particulate matter.

- Saravanan (2010) analysed the combustion characteristics of crude rice bran oil methyl ester blend in a direct injection compression ignition engine and found that the cylinder pressure was comparable where as the delay period and the maximum rate of pressure rise were lower than that of diesel.

- Ismet Celikten (2010) Compared the performance and emissions of diesel fuel from rapseed and soybean oil methyl esters injected at different pressures(250,300 and 350 bar). It has been found that the torque and power of diesel fuel engine reduced with increasing injection pressure. It can be seen that, when the injection pressure is increased, smoke level is reduced up to $89 \%$. The lowest smoke emission was obtained with 350 bar injection pressure. $\mathrm{CO}$ emission is reduced by $26 \%$ when the injection pressure is increased. However, $\mathrm{NO}_{\mathrm{X}}$ emission is increased with higher injection pressure by $26 \%$. This may be caused by increasing in combustion temperature and speed of flame in especially higher engine speed.

\section{Bio Diesel Production Process}

The chemical process commonly used make bio-oils less viscous, turning them into "biodiesel" is called "Transesterification" [8].

\section{A. Transesterification Process}

Hibiscus oil was used as the raw oil to be transesterified with methanol in a reacting tank. The temperature values are below the boiling point of methanol $\left(63^{\circ} \mathrm{C}\right)$, to prevent the methanol in the reactant mixture from evaporating [9].

The potassium hydroxide was stirred with methanol for 10 minutes using an electric-magnetic stirrer to form potassium methoxide, which was then poured into the reacting tank and mixed with the hibiscus oil [10]. The total reaction time was 60 minutes. Almost total conversion to hibiscus oil bio diesel was achieved quickly after a few minutes from the start of the reaction, depending on the ambient conditions.

The chemical formula for biodiesel Transesterification is:

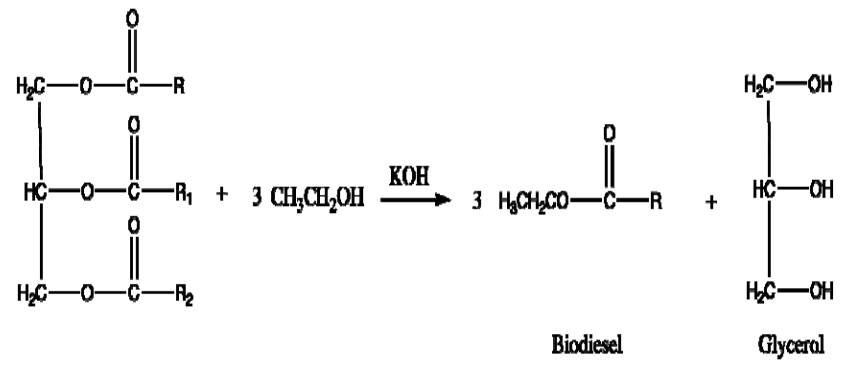

\section{B. Properties of biodiesel comparison with diesel}

\begin{tabular}{|c|c|c|}
\hline Properties & Hibiscus oil & Pure diesel \\
\hline $\begin{array}{c}\text { Density at } 15^{\circ} \mathrm{c} \\
\left(\mathrm{kg} / \mathrm{m}^{3}\right)\end{array}$ & 746.9 & 843 \\
\hline $\begin{array}{c}\text { Viscosity at } 40^{0} \mathrm{c} \\
(\text { Centi stokes })\end{array}$ & 4.26 & 4.3 \\
\hline $\begin{array}{c}\text { Flash point } \\
\left({ }^{0} \mathrm{C}\right)\end{array}$ & 182 & 54 \\
\hline $\begin{array}{c}\text { Fire point } \\
\left({ }^{0} \mathrm{C}\right)\end{array}$ & 497 & $50-55$ \\
\hline $\begin{array}{c}\text { Cetane number } \\
\text { Calorific value } \\
(\mathrm{KJ} / \mathrm{kg})\end{array}$ & 37,178 & 44,800 \\
\hline
\end{tabular}

\section{EXPERIMENTAL INVESTIGATION}

In order to evaluate and compare the performances and emission characteristics of the fuel, the experiments were conducted using a VCR diesel engine in thermal laboratory. This section deals with description of the experimental set up, various instruments and software used for testing.

\section{A. Description of test rig}

The diesel engine is a high speed, four stroke, vertical, water cooled type. The loading is by means of an electrical dynamometer. The fuel tank is connected to graduated burette to measure the quantity of fuel consumed in unit time. 
An orifice meter with U-tube manometer is provided along with an air tank on the suction line for measuring air consumption. An PEA205 smoke meter is provided for measuring emissions for exhaust gases. The test rig is installed with ENGINE TEST TED software for obtaining various curves and results during operation. A fine gas analyser is used to obtain the exhaust gas composition.

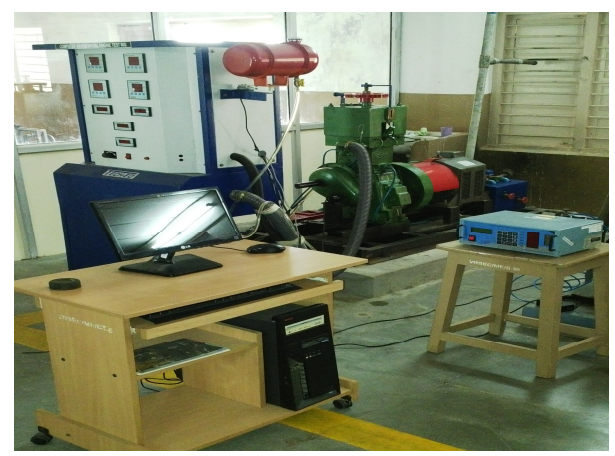

\section{B. Test engine specifications}

Type: four stroke single cylinder vertical water cooled diesel engine.

TABLE I

\begin{tabular}{|c|c|}
\hline Rated power & $3.7 \mathrm{KW}$ \\
\hline Rated speed & $1500 \mathrm{rpm}$ \\
\hline Bore Dia (D) & $80 \mathrm{~mm}$ \\
\hline Stroke(L) & $110 \mathrm{~mm}$ \\
\hline Compression ratio & $12: 1$ to $20: 1$ \\
\hline Orifice diameter & $13.6 \mathrm{~mm}$ \\
\hline $\begin{array}{l}\text { Coefficient of } \\
\text { discharge }\left(\mathrm{C}_{\mathrm{d}}\right)\end{array}$ & 0.6 \\
\hline
\end{tabular}

\section{Test methodology}

The present set of experiments was conducted on a four stroke single cylinder vertical water cooled diesel engine equipped with a computer. First the maximum torque of the engine is calculated and the engine is started under no load condition by hand cranking using de-compression lever. The engine will run under no load condition for a few minutes so that the speed stabilizes at rated value.

Now by increasing the load from zero to maximum and setting the compression ratio to $13.5,16.5$ and 18 the respected values are automatically saved in a computer and also the exhaust emissions are noted down by using digital gas analyzer indicator. The two types of blends (B15, B25) were used in this experiment. The different parameters required for evaluation of fuel was noted.

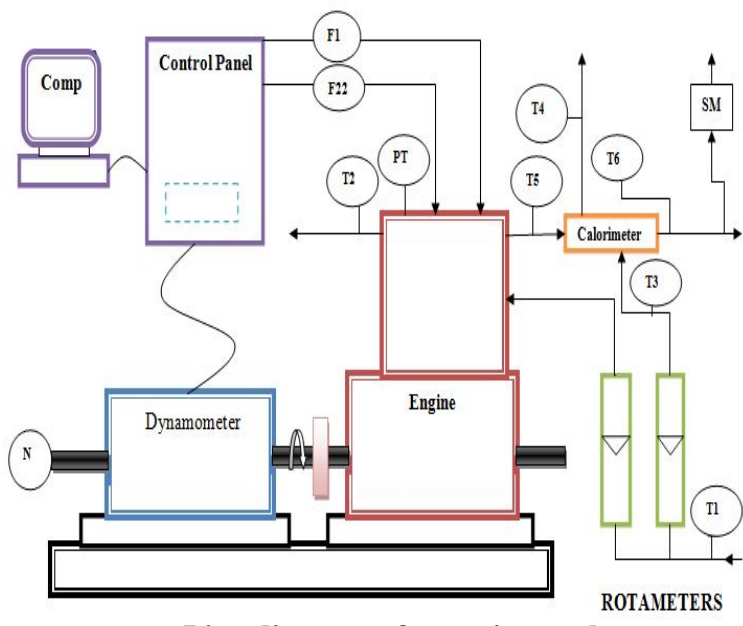

Line diagram of experimental setup

F1 Fuel flow unit

F2 Air flow unit

F4 calorimeter water flow $\mathrm{kg} / \mathrm{hr}$

T1, T3 Inlet water temperature ${ }^{\circ} \mathrm{k}$

$\mathrm{T} 2 \quad$ Outlet engine jacket water temperature ${ }^{\circ} \mathrm{k}$

T4 Calorimeter water outlet temperature ${ }^{\circ} \mathrm{k}$

T5 Exhaust gas to calorimeter inlet temp ${ }^{\circ} \mathrm{k}$

T6 Exhaust gas from calorimeter outlet temp ${ }^{\circ} \mathrm{k}$

\section{Results and discussions}

\section{Performance characteristics:}

Fig.1 shows the variation of brake thermal efficiency with respect to brake power for blends and pure diesel at CR13.5 shows that Brake thermal efficiency of B 25 blend is higher as compared to that of diesel and B15. It has been observed that the brake thermal efficiency of the blends is increasing with increase in applied load. It was happened due to reduction in heat loss and increase in power developed with increase in load. The maximum brake thermal efficiency at full load is $38.3 \%$ for B25 at CR 13.5 which is $8 \%$ higher than that of diesel.

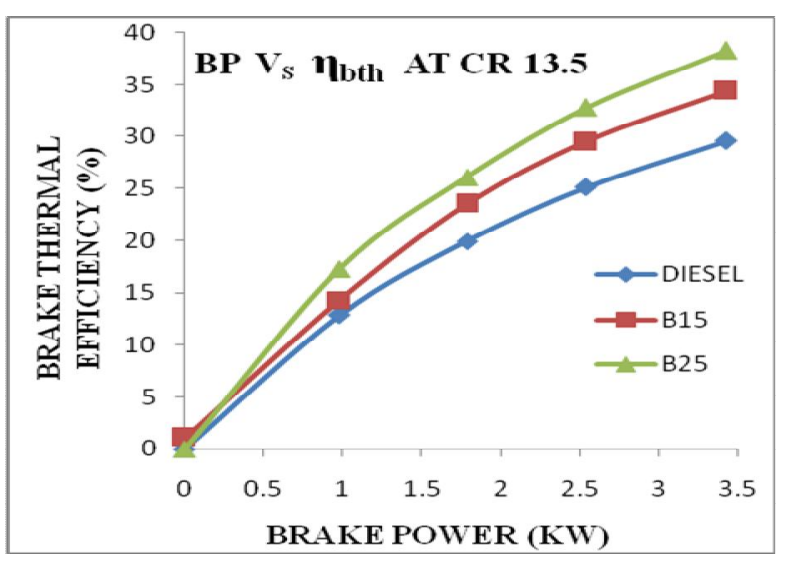

Fig.1 Brake thermal efficiency against Brake power at CR 13.5 
Fig.2 shows the variation of brake thermal efficiency with respect to brake power for blends and pure diesel at CR 16.5 shows that Brake thermal efficiency of B 25 blend is higher as compared to that of diesel. It has been observed that the brake thermal efficiency of the blends is increasing with increase in applied load and the max brake thermal efficiency is $43.1 \%$. The increase in brake thermal for higher blends may be due to the improved atomization fuel vaporization and frictional losses decrease

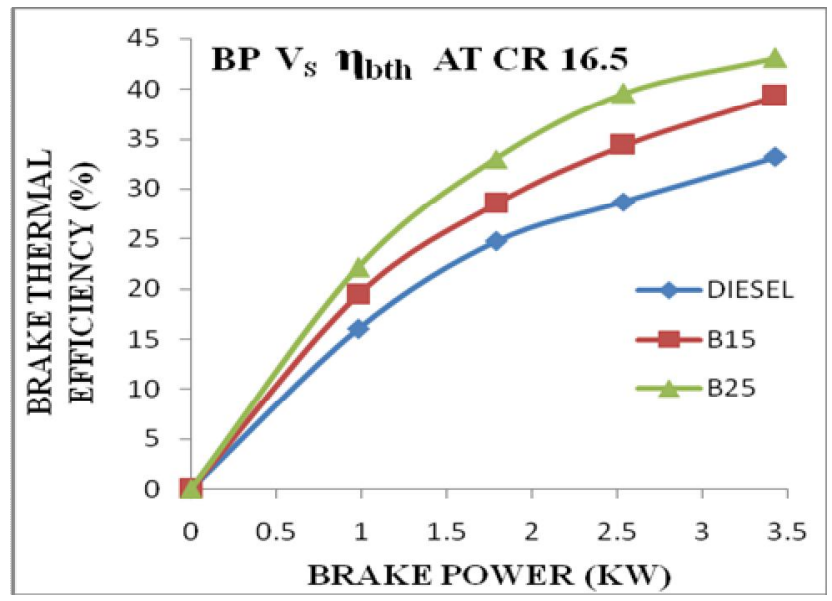

Fig.2 Brake thermal efficiency against Brake power at CR 16.5

Fig.3 shows the variation of brake thermal efficiency with respect to brake power for blends and pure diesel at CR 18 shows that Brake thermal efficiency of B 25 blend is higher as compared to that of diesel. It has been observed that the brake thermal efficiency of the blends is increasing with increase in applied load and the max brake thermal efficiency is $40.8 \%$. The increase in brake thermal for higher blends may be due to the combined effect of its higher heating value and decrease in fuel consumption.

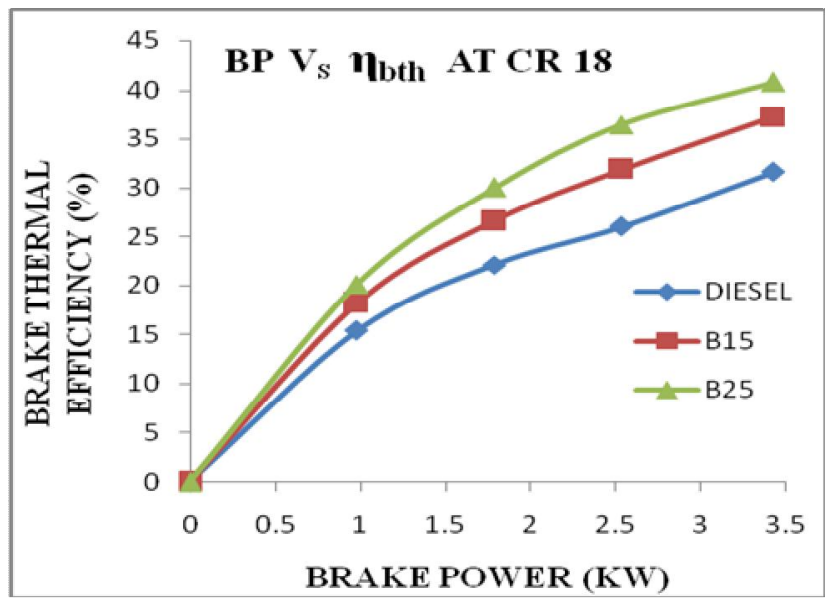

Fig. 3 Brake thermal efficiency against Brake power at CR 18
Fig.4 shows the mechanical efficiency variation with brake power for the hibiscus oil blends and diesel at CR 13.5. It can be seen that in the beginning with increasing load of the engine the mechanical efficiency of various concentration of blends and pure diesel were increased. The maximum mechanical efficiency of the engine was $63 \%$ for hibiscus oil B25 at full load where it is slightly less for diesel which is $56.5 \%$. This is due to improved atomization fuel vaporization, better spray characteristics and improved combustion through mixture.

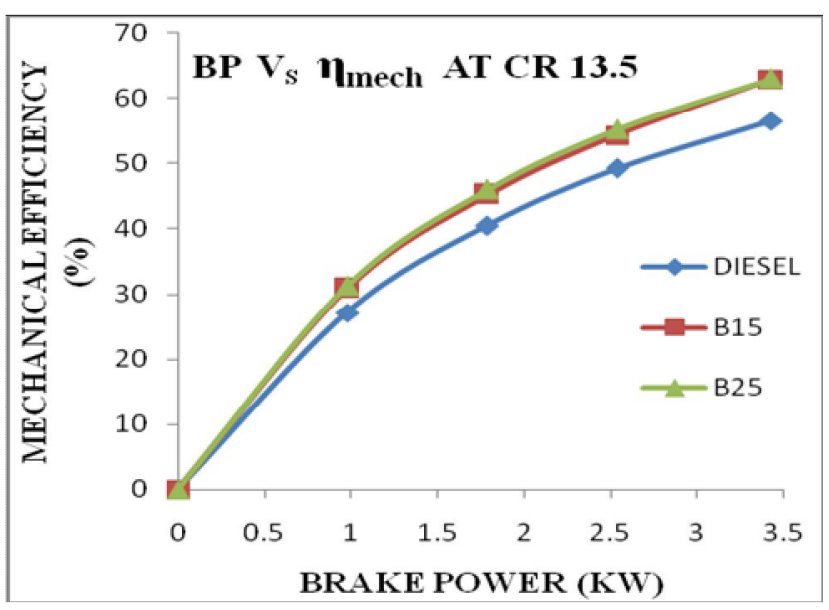

Fig.4 Mechanical efficiency against Brake power at CR 13.5

Fig. 5 shows Mechanical efficiency against brake power at CR 16.5 for the hibiscus oil blends and pure diesel. It is observed that the mechanical efficiency for diesel is found to increase with increase in load. Among the blends B15 and B25 shows the maximum mechanical efficiency is achieved at full load for B15 that is $64.8 \%$ than other blends and pure diesel. The minimum mechanical efficiency is observed for diesel at full load condition. The increase in efficiency is may be decrease in heat loss due to low frame temperature of blends than that of diesel.

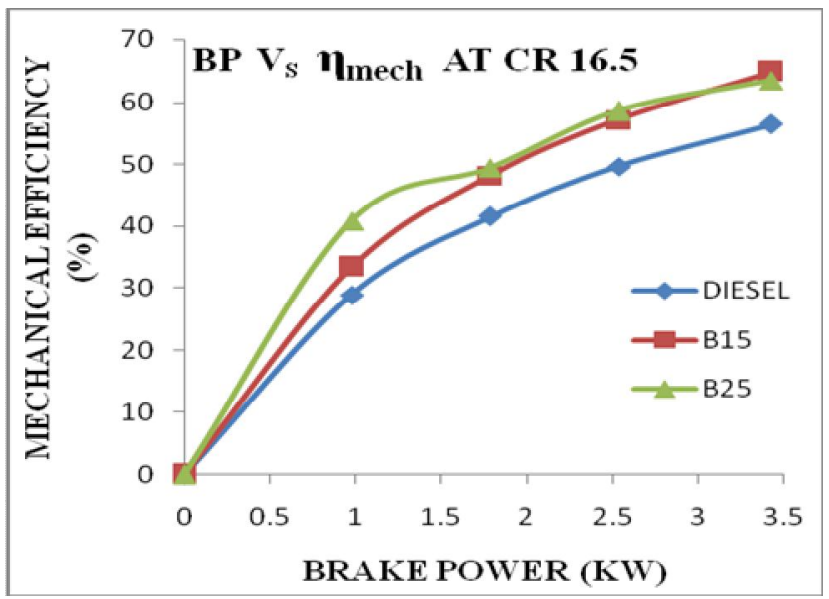

Fig. 5 Mechanical efficiency against Brake power at CR 16.5 
Fig. 6 shows Mechanical efficiency against brake power at CR 18 for the hibiscus oil blends and pure diesel. It is observed that the mechanical efficiency for diesel is found to increase with increase in load. Among the blends B15 and B25 shows the maximum mechanical efficiency is achieved at full load for B25 that is $65.8 \%$ than other blends and pure diesel. The minimum mechanical efficiency is observed for diesel at full load condition. This may due to better combustion and an increase in the energy content of the blend.

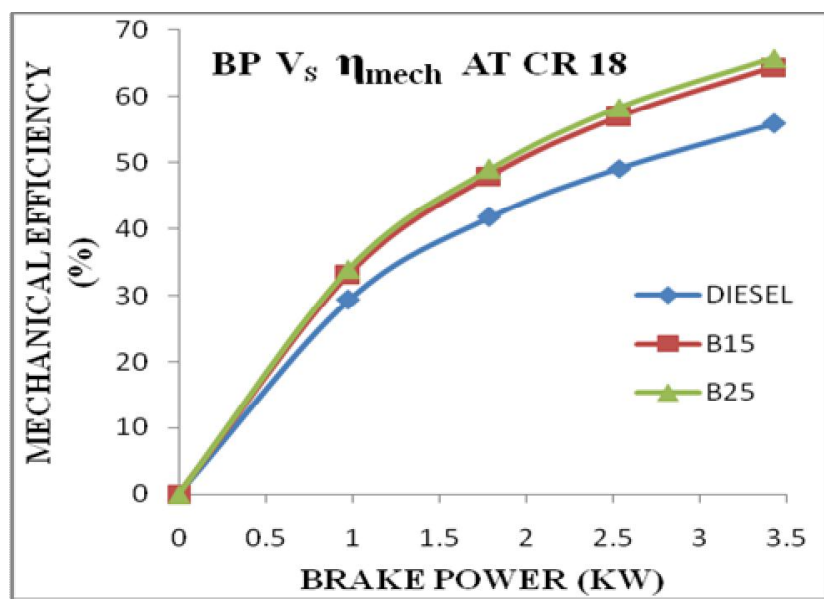

Fig. 6 Mechanical efficiency against Brake power at CR 18

Fig. 7 shows Exhaust gas temperature against brake power at CR 13.5 for the hibiscus oil blends and pure diesel. It is observed that the exhaust gas temperature for diesel is found to increase with increase in load. Among the blends B15 and B25 shows relatively less exhaust temperatures than diesel. The maximum exhaust temperature is obtained for diesel which is $445^{\circ} \mathrm{c}$ which is high as compared to $407^{\circ} \mathrm{c}$ of B15. The increase in temperature is may be due to longer ignition delay.

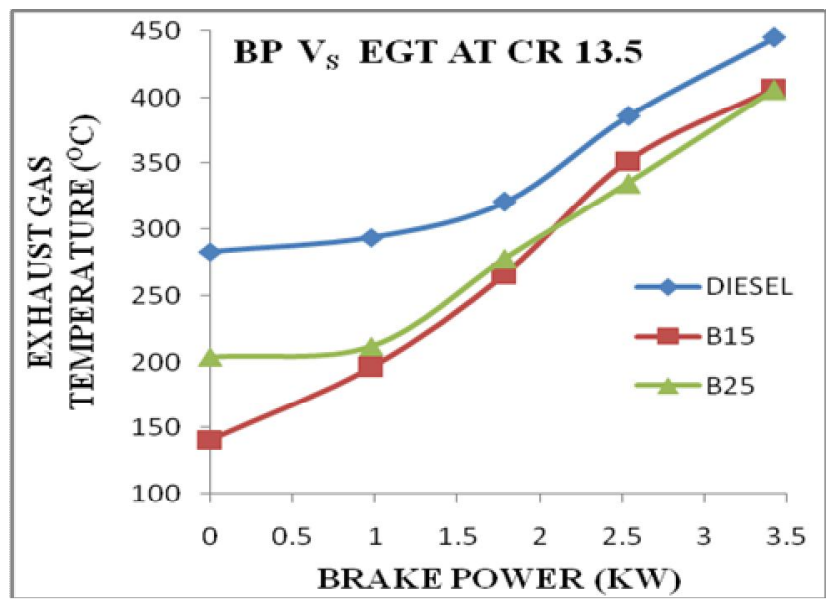

Fig. 7 Exhaust gas temperature against Brake power at CR 13.5

Fig. 8 shows Exhaust gas temperature against brake power at CR 16.5 for the hibiscus oil blends and pure diesel. It is observed that the exhaust gas temperature for diesel is found to increase with increase in load. Among the blends B15 and B25 shows relatively less exhaust temperatures than diesel. The maximum exhaust temperature is obtained for diesel which is $479^{\circ} \mathrm{c}$ which is high as compared to $458^{\circ} \mathrm{c}$ of $\mathrm{B} 25$. The relatively higher boiling point constituents were not adequately evaporated during the main combustion phase and continued to burn in the late combustion phase.

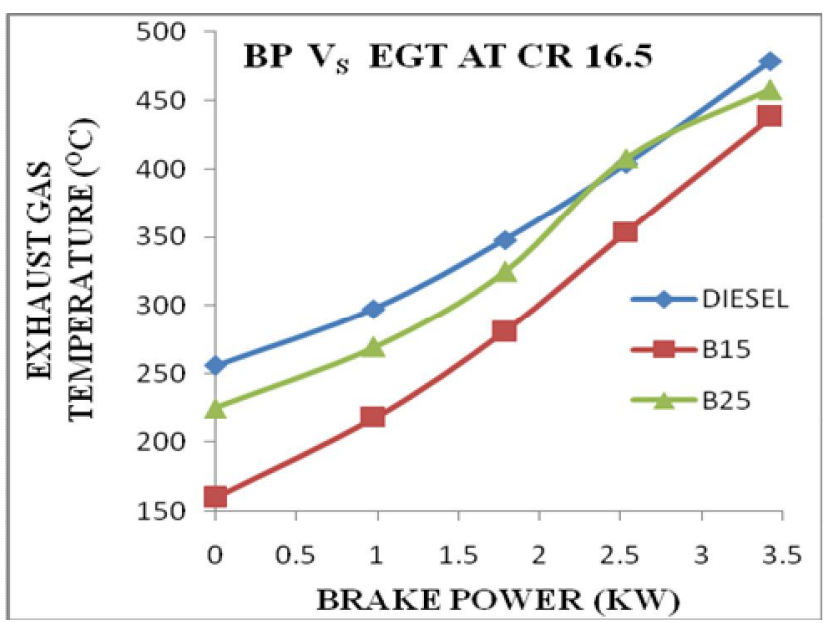

Fig. 8 Exhaust gas temperature against Brake power at CR 16.5

Fig. 9 shows Exhaust gas temperature against brake power at CR 18.5 for the hibiscus oil blends and pure diesel. It is observed that the exhaust gas temperature for diesel is found to increase with increase in load. Among the blends B15 and B25 shows relatively less exhaust temperatures than diesel. The maximum exhaust temperature is obtained for diesel which is $459^{\circ} \mathrm{c}$ which is high as compared to $435^{\circ} \mathrm{c}$ of B25. This increase in temperature may be due to un burnt fuel which is coming out as oxides of nitrogen, sulphur and carbon.

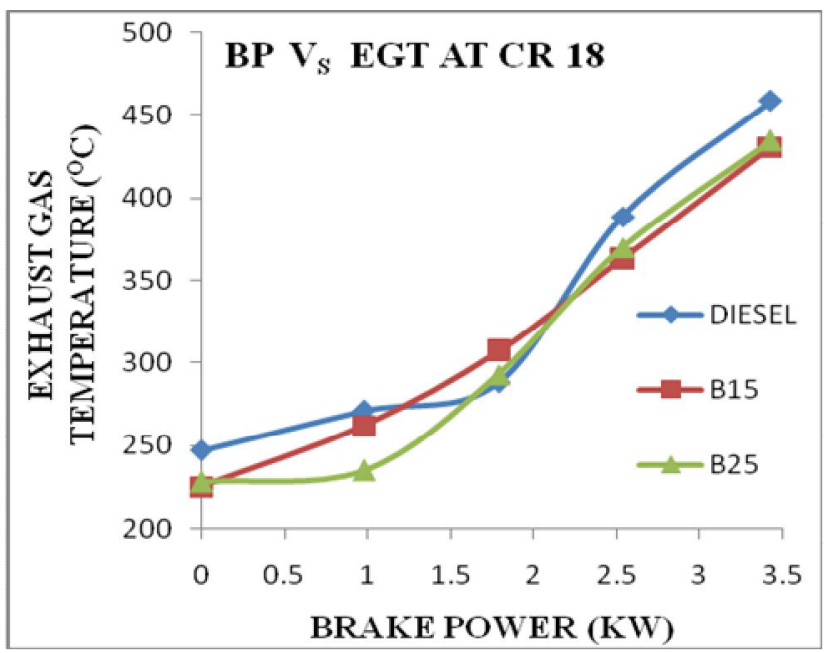

Fig. 9 Exhaust gas temperature against Brake power at CR 18 


\section{Emission Characteristics}

Fig.10 shows the variation of carbon monoxide with brake power for the hibiscus oil blends and diesel. The CO emission of the blend B25 is less than the standard diesel at full load condition and it is found to be higher for the blend B15. Emission for the blend B25 and diesel comes exactly the same at $3 / 4^{\text {th }}$ load. The percentage of $\mathrm{CO}$ increases due to rising temperature in the combustion chamber, physical and chemical properties of the fuel, air-fuel ratio, shortage of oxygen at high speed.

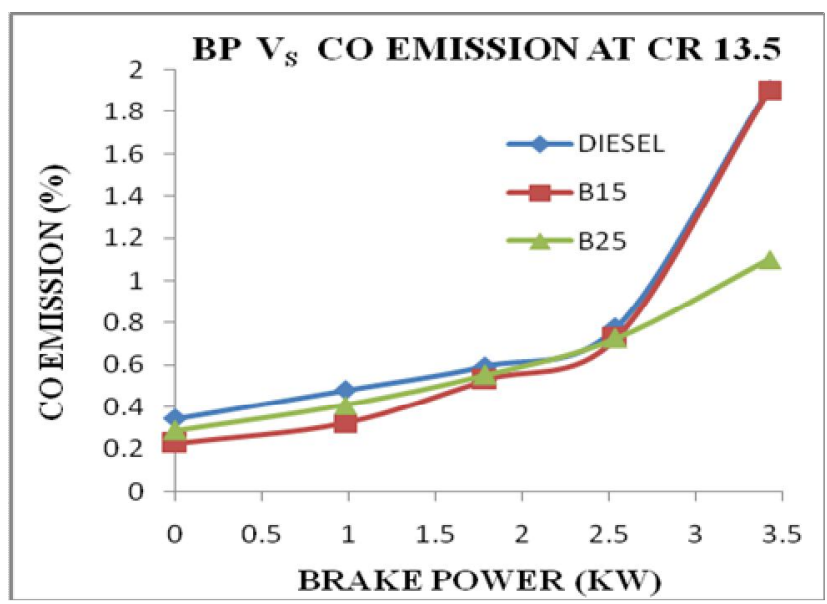

Fig.10 Carbon monoxide against Brake power at CR 13.5

Fig.11 shows the variation of carbon monoxide with load for the hibiscus oil blends and diesel. The $\mathrm{CO}$ emission of the blend B15 and B25 is less than the standard diesel at CR16.5 for full load condition and at half load emission has been slightly increased for blend B15 the percentage of $\mathrm{CO}$ increases due to less amount of time available for complete combustion.

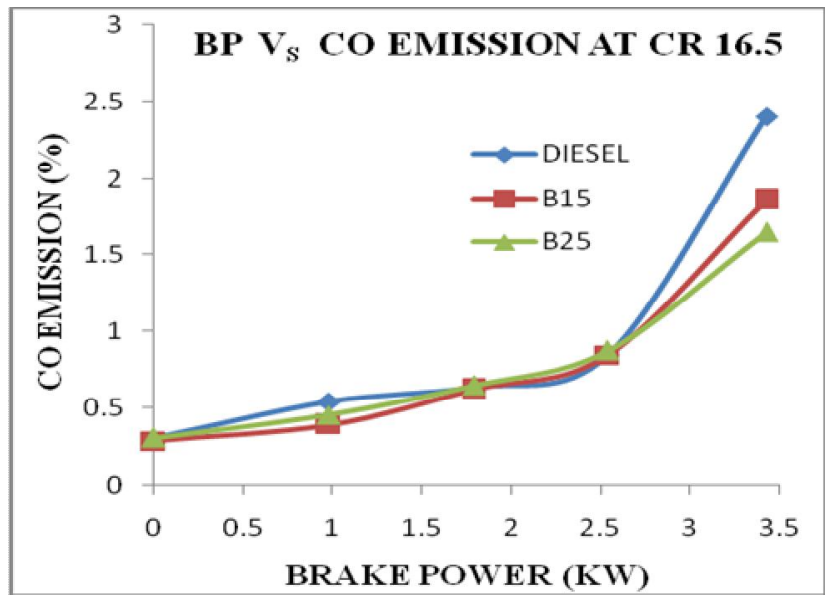

Fig.11 Carbon monoxide against Brake power at CR 16.5
Fig.12 shows the variation of carbon monoxide with load for the hibiscus oil blends and diesel. The $\mathrm{CO}$ emission of the blend B15 and B25 is less than the standard diesel at CR 18 for full load condition and at half load emission has been slightly increased for blend B15 the percentage of $\mathrm{CO}$ increases may be due to poor vaporization and atomization.

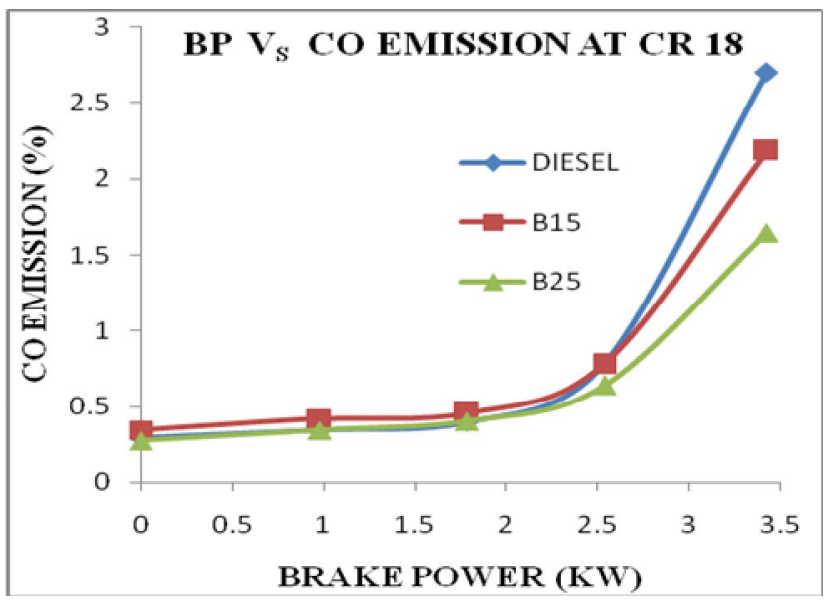

Fig.12 Carbon monoxide against Brake power at CR 18

Fig. 13 shows the variation of Carbon dioxide with brake power of the engine. The $\mathrm{CO}_{2}$ emission for B15 and B25 has been increased than that of diesel and at full load the emissions of diesel are close to that of blends. The reason for increase in $\mathrm{CO}_{2}$ is may be due to efficient combustion inside the combustion chamber.

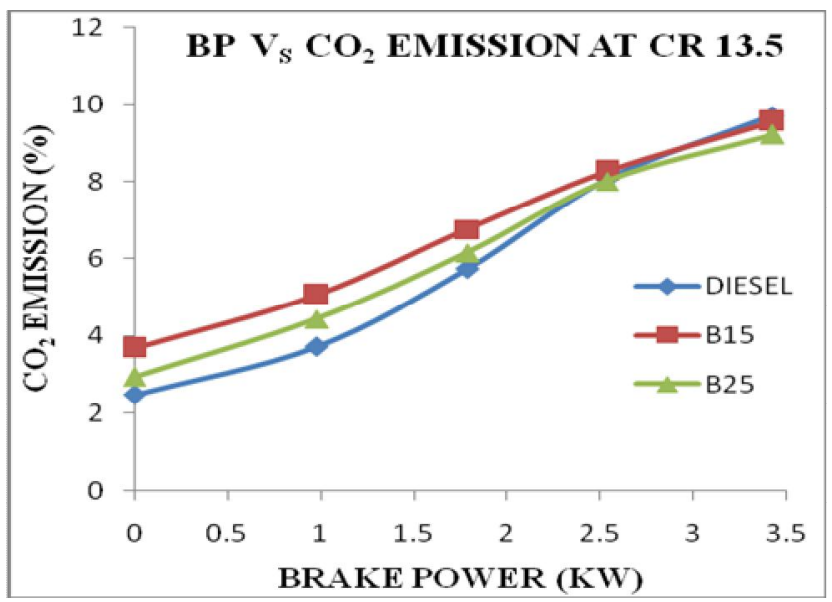

Fig. 13 Carbon dioxide against Brake power at CR 13.5

Fig. 14 shows the variation of Carbon dioxide with brake power of the engine. The $\mathrm{CO}_{2}$ emission for $\mathrm{B} 15$ and $\mathrm{B} 25$ has been increased than that of diesel and at full load the emissions of diesel are close to that of blends. The reason for the increase in $\mathrm{CO}_{2}$ is may be due to increase in compression ratio from 13.5 to 16.5 the $\mathrm{CO}$ Emission reacts with extra oxygen and thus resulting in high $\mathrm{CO}_{2}$. 


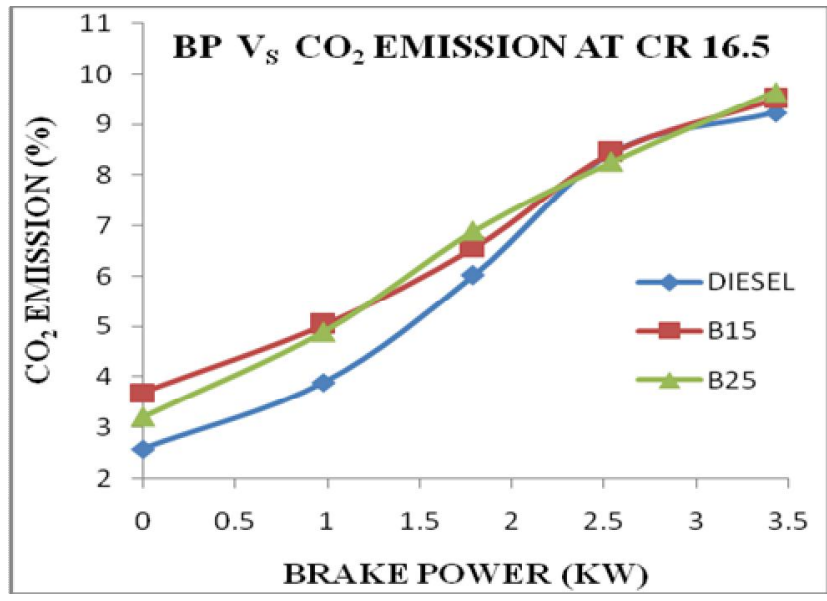

Fig.14 Carbon dioxide against Brake power at CR 16.5

Fig. 15 shows the variation of Carbon dioxide with brake power of the engine. Initially B25 Emission is less than that of diesel and by increasing the loads the $\mathrm{CO}_{2}$ increased gradually and thus resulting in higher emissions than the diesel. The reason for the increase in emission at CR18 is may be due to abundant availability of oxygen in the air.

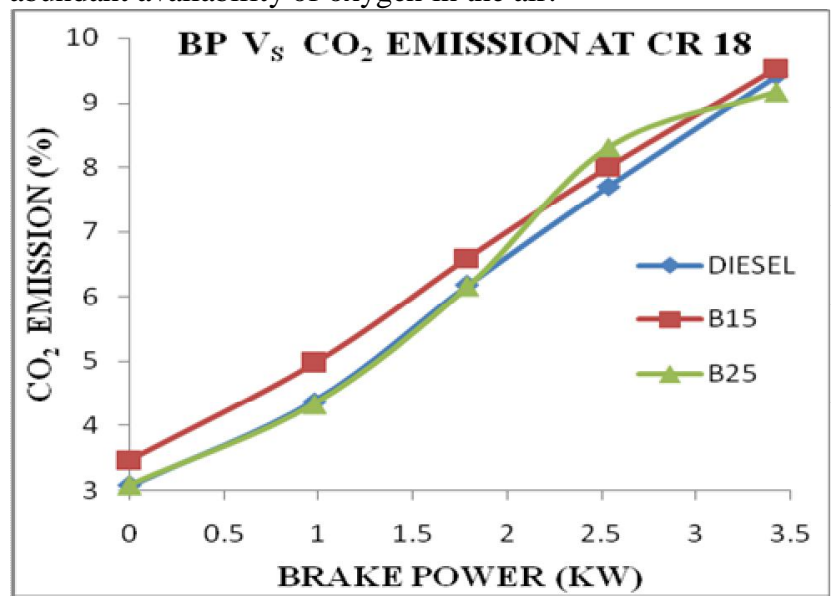

Fig.15 Carbon dioxide against Brake power at CR 18

Fig.16 shows the variation of Nitrogen Oxide with brake power of the engine. It is observed that Nitrogen oxide emission increase with increase of load. The Minimum nitrogen oxide value was $101 \mathrm{ppm}$ for diesel and where as it was $195 \mathrm{ppm}$ for B25. This is a result of low availability of oxygen during combustion.

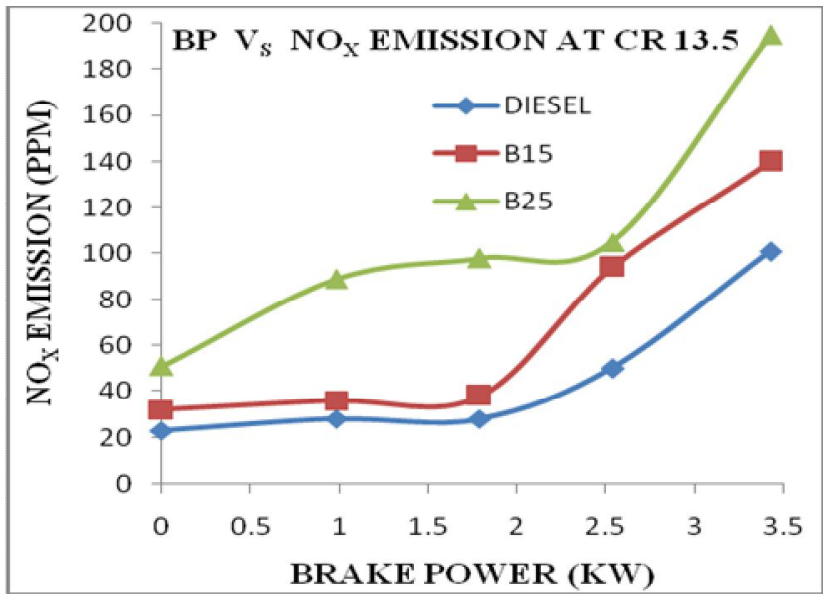

Fig. 16 Nitrogen oxide against Brake power at CR 13.5

Fig.17 shows the Nitrogen oxide variation with brake power for the hibiscus oil blends and diesel. The Nitrogen oxide emissions are higher for blends of hibiscus oil compared with diesel. The lowest value of $\mathrm{NO}_{\mathrm{X}}$ was $120 \mathrm{ppm}$ for diesel at full load as compared to B25 with176ppm. This result depends on oxygen quantity and fuel viscosity, in turn atomization. $\mathrm{NO}_{\mathrm{X}}$ emissions are mainly governed by the magnitude of peak cylinder temperature and crank angle at which it occurs.

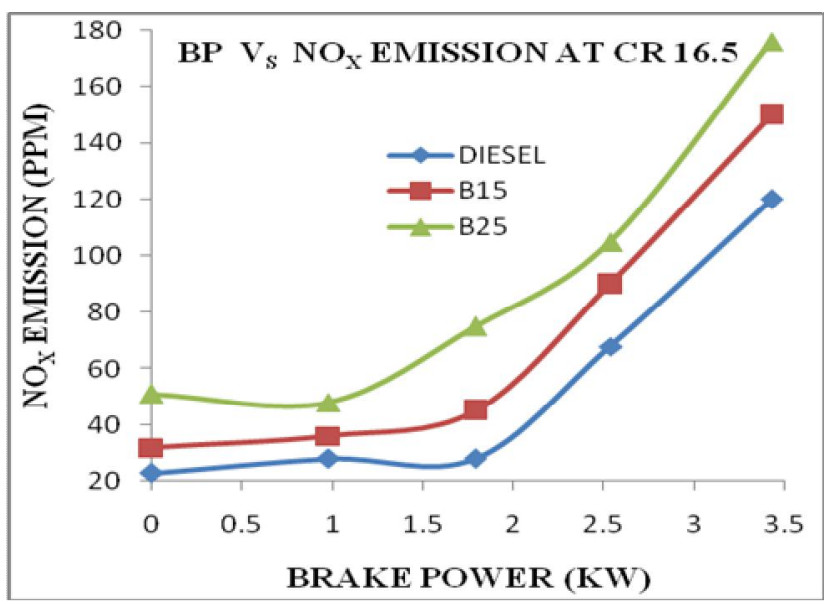

Fig. 17 Nitrogen oxide against Brake power at CR 16.5

Fig.18 shows the Nitrogen oxide variation with brake power for the hibiscus oil blends and diesel. The Nitrogen oxide emissions are lower for all the blends of hibiscus oil compared with diesel. The lowest value of $\mathrm{NO}_{\mathrm{X}}$ was $98 \mathrm{ppm}$ for diesel at full load as compared to B25 with 180ppm. This reason for increase in $\mathrm{NO}_{\mathrm{X}}$ Emissions is high temperature and better availability of oxygen. The oxygen contain in the biodiesel facilitate in the oxidation of the nitrogen present in the air resulting in the formation of the $\mathrm{NO}_{\mathrm{X}}$. 


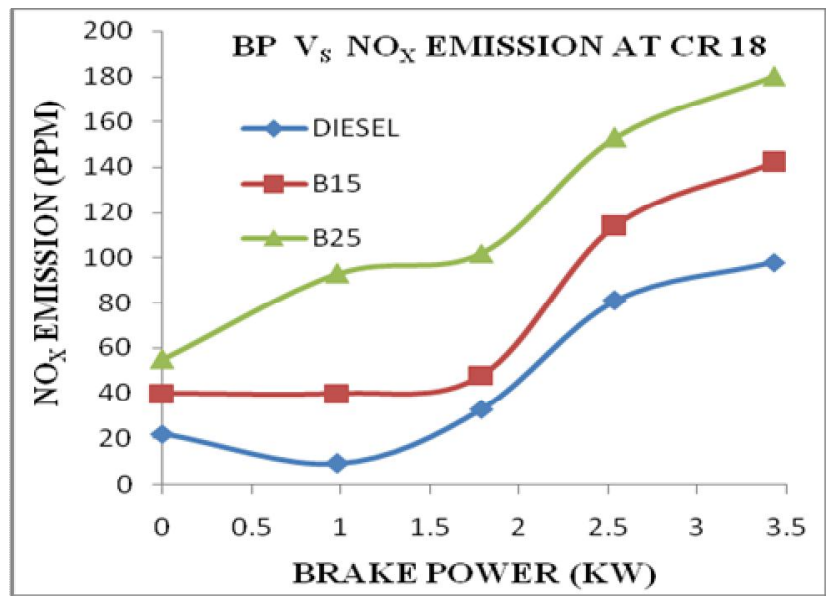

Fig. 18 Nitrogen oxide against Brake power at CR 18

\section{Conclusions}

The performance and emission characteristics of diesel and bio diesel were investigated on four stroke single cylinder vertical water cooled diesel engine. The conclusions of this investigating at are as follows.

1. The brake thermal efficiency at compression ratios 13.5 , 16.5 and 18 tend to increase with the load such that B25 has performed well in acquiring the highest brake thermal efficiency and the maximum brake thermal efficiency obtained is $43.1 \%$ at CR 16.5 at brake power $3.47 \mathrm{KW}$ and CR 18 also performed similarly to CR 16.5. This is may be due to improved atomization fuel vaporization, better spray characteristics and improved combustion through mixture. With increase in compression ratio, the brake thermal efficiency increases. As the compression ratio is increased, the heat loss to the combustion chamber wall and frictional losses decrease, hence, there is an improved performance at higher compression ratio.

2. The mechanical efficiency at compression ratio $13.5,16.5$ and 18 tend to increase with the load and B25 at CR 18 has the highest mechanical efficiency of $65.8 \%$. The increase in efficiency for all the biodiesel blends may be due to improved quality of spray, high reaction activity in the fuel rich zone and decrease in heat loss due to lower flame temperature of the blends than that of diesel.

3. The exhaust gas temperature was observed lowest with $15 \%$ hibiscus oil diesel blend at CR 13.5 at low as well as at high loads. However, Results show that the exhaust gas temperature increases with the load. Similar trends were observed for all hibiscus oil diesel blends. As seen in graphs the highest exhaust gas temperature at peak load was found for diesel at CR 18. This may be because vegetable oils usually comprise constituents that have higher boiling points. These relatively higher boiling point constituents were not adequately evaporated during the main combustion phase and continued to burn in the late combustion phase. This resulted in higher exhaust gas temperatures. The longer ignition delay may also result in higher combustion temperatures as well as higher exhaust temperatures.

4. In the carbon monoxide emission graphs at all compression ratios the emissions are much lesser than diesel and the highest emission is $2.7 \%$ for diesel at CR 18 (full load) and similarly the lowest emission is $0.2 \%$ for B15 at CR 13.5(no load). The reason for increase in emission is may be incomplete due to shortage of air or due to low gas temperature. Although the high concentration fuel blends contains less carbon content in fuel but due to inferior combustion on the account of poor vaporization and atomization leads to increase in carbon monoxide in exhaust at high concentration blends.

5. The carbon dioxide emissions have been gradually increased than diesel this is due to complete combustion of the mixture inside the cylinder. Due to efficient combustion and injection timing, higher level of carbon dioxide emissions found in exhaust.

6. $\mathrm{NO}_{\mathrm{X}}$ emission increased for blends $\mathrm{B} 15$ and B25 compared to diesel at all compression ratios the highest $\mathrm{NO}_{\mathrm{X}}$ emitted is $197 \mathrm{PPM}$ at CR 13.5 for B25. The main reason for the formation of oxides of nitrogen in diesel engines is high temperature and better availability of oxygen. The oxygen contain in the biodiesel facilitate in the oxidation of the nitrogen present in the air resulting in the formation of the $\mathrm{NO}_{\mathrm{X}}$.

\section{REFERENCES}

[1] Xavier Tauzia, Alain Maiboom and Samiur Rahman Shah, "Experimental Study of Inlet Manifold Water Injection on Combustion and Emissions of an Automotive Direct Injection Diesel Engine", Journal of Energy, Volume 35, 2010, Pages 3628-3639.

[2] B. K. Venkanna, Swati B., Wadawadagi and C. Venkataramana Reddy, "Effect of Injection Pressure on Performance, Emission and Combustion Characteristics of Direct Injection Diesel Engine Running on Blends of Pongamia Pinnata Linn Oil (Honge oil) and Diesel Fuel", Agricultural Engineering international, The CIGR E-journal, Manuscript Number 1316, Volume. XI, May, 2009.

[3] Venkatraman M. and Devaradjane G., "Effect of Compression Ratio, Injection Timing and Injection Pressure on a DI Diesel engine for better performance and emission fueled with diesel diesel biodiesel blends", International Journal of Applied Engineering Research, Dindigul, Volume 1, No 3, 2010, pages 288-298.

[4] Elango T. and Senthilkumar T., "Effect of Methyl Esters of Neem and Diesel Oil Blends on the Combustion and Emission Characteristics of a C.I. Engine", ARPN Journal of Engineering and Applied Sciences, Volume 5, No. 10, 2010, Pages 80-85.

[5] Tamilvendhan D. and Ilangovan V., "Performance, Emission and Combustion Characteristics of a Methyl Ester Sunflower Oileucalyptus Oil in a Single Cylinder Air Cooled and Direct Injection Diesel Engine", International Journal of Engineering Science and Technology, Volume 3, 2011, Pages 1977-1985.

[6] Ekrem Buyukkakaya and Muhammet Cerit, "Experimental Study of NOx Emissions and Injection Timing of a Low Heat Rejection Diesel Engine", International Journal of Thermal Sciences, volume 47, 2008, pages 1096- 1106.

[7] Kamal Kishore Khatri, Dilip Sharma, S. L. Soni, Satish Kumar and 
Deepak Tanwar, "Investigation of Optimum Fuel Injection Timing of Direct Injection CI Engine Operated on Preheated Karanj-Diesel Blend", Jordan Journal of Mechanical and Industrial Engineering, Volume 4, Number 5, 2010, Pages 629-640.

[8] T. K. Kannan and R. Marappan, "Study of Performance and Emission Characteristics of a Diesel Engine using Thevetia Peruviana Biodiesel with Diethyl Ether Blends", European Journal of Scientific Research, Volume 43, 2010, Pages 563-570.

[9] S. Sundarapandian and G. Devaradjane, "Performance and Emission Analysis of Bio-Diesel Operated CI Engine", Journal of Engineering, Computing and Architecture, Volume 1, Issue 2, 2007, Pages 1-22.

[10] M. Pugazhvadivu and G. Sankaranarayanan, "Experimental Studies on a Diesel Engine Using Mahua Oil as fuel", Indian Journal of Science and Technology, Volume 3, 2010, Pages 787-791.

[11] Tripathi R. K. and Sahoo P. K., "Performance Evaluation of a Low Speed IDI Engine Fueled with Diesel and Jatropha Straight Vegetable Oil", International Journal of Science Technology \& Management, Volume 2, Issue 2, April 2011.

[12] Avinash Kumar Agarwal, "Biofuels (Alcohols and Biodiesel): Applications as Fuels for Internal Combustion Engines", Progress in Energy and Combustion Science, Volume 33, 2007, Pages 233-271 